Tropical Journal of Pharmaceutical Research August 2010; 9 (4): 395-399

(C) Pharmacotherapy Group,

Faculty of Pharmacy, University of Benin

Benin City, 300001 Nigeria.

All rights reserved.

Research Article

Available online at http://www.tjpr.org

\title{
A Comparative Study of the Pharmacokinetics of Conventional and Sustained-release Tablet Formulations of Aceclofenac in Healthy Male Subjects
}

\author{
Santanu Ghosh* and BB Barik \\ University Department of Pharmaceutical Sciences, Utkal University, Bhubaneswar, Orissa.-751004, India.
}

\begin{abstract}
Purpose: To examine the pharmacokinetics of a formulated aceclofenac sustained release tablet formulation and determine if it is bioequivalent to a commercial brand of aceclofenac immediate release tablet (Zerodo ${ }^{\circledR} 100 \mathrm{mg}$ ).

Methods: Each of two groups of twelve fasting volunteers received either the reference standard (Zerodol $100 \mathrm{mg}$ tablets) or the test formulation (200 mg aceclofenac) orally once, using a cross-over design with a one week wash-out period. Their blood samples were obtained at regular time intervals over $24 h$ and analyzed by high performance liquid chromatography (HPLC). Using the noncompartmental approach, plasma levels of aceclofenac were employed to compute their individual disposition kinetics, including peak plasma concentration $\left(C_{\max }\right)$, peak time $\left(T_{\max }\right)$, area under the plasma level-time curve $\left(A \cup C_{0-t}\right)$, elimination rate constant $\left(K_{e l}\right)$ and elimination half life $\left(t_{1 / 2}\right)$.

Results: The $C_{\max }$ values of $11043 \pm 3073 \mathrm{ng} / \mathrm{ml}$ and $12301 \pm 3000 \mathrm{ng} / \mathrm{ml}$ were attained in $2.58 \pm 1.22$ $h$ and $1.29 \pm 0.75 h$ for the test and reference products, respectively, while $A U C_{0-\infty}$ was $45996 \pm 10427$ and $50253 \pm 8283 \mathrm{ng} . \mathrm{h} / \mathrm{ml}$, respectively. At 90\% confidence interval, the $C_{\max }$, AUC 0 -t and AUC $\mathrm{C}_{0-\infty}$ values of the test preparation were 96.4 - 101.3, $100.2-101.9$ and $98.5-99.8 \%$, respectively, of the values for the reference. The $t_{1 / 2}$ values were found to be $4.50 \pm 1.25$ and $2.20 \pm 2.59 \mathrm{~h}$ for the reference and test products.

Conclusion: On the basis of the pharmacokinetic data, it can be said that the test aceclofenac sustained release formulation and the reference product were bioequivalent in some respects. However, the test formulation exhibited a longer elimination half-life $\left(t_{1 / 2}\right)$, thus demonstrating sustained release properties, unlike the reference.
\end{abstract}

Keywords: Pharmacokinetics; Bioequivalence; Sustained release aceclofenac formulation. 


\section{INTRODUCTION}

Aceclofenac is a relatively new phenylacetic acid derivative showing marked antiinflammatory, anti-arthritic, analgesic and anti-rheumatic activities [1]. The drug demonstrates better gastric tolerance than other non steroid anti-inflammatory drugs (NSAIDs) such as indomethacin and diclofenac [2]. Its recommended dose is 100 mg twice a day orally in the form of tablets. After oral administration, it is rapidly absorbed and bioavailability is almost $100 \%$ [3]. Peak plasma concentrations are reached within 1.25 to $3 \mathrm{~h}$ following ingestion [3]. It is highly protein-bound (> $99.7 \%$ ) and penetrates into the synovial fluid, where the concentration reaches up to approximately $60 \%$ of that in plasma [3]. The volume of distribution is approximately $30 \mathrm{~L}$ while mean plasma elimination half-life and clearance are $4.3 \pm 0.3 \mathrm{~h}$ and $5 \mathrm{~L} / \mathrm{h}$, respectively [3].

Aceclofenac is probably metabolized via Cytochrome P450 2C9 (CYP2C9, a protein encoded by the CYP2C9 gene in humans) to the main metabolite 4-hydroxyacefenac with negligible contribution to clinical activity [3]. Its adverse reactions, as with other NSAIDs taken by mouth, are indigestion, heartburn, nausea and diarrheoa [3].

The objective of this study was to examine the in vivo bioequivalence of a test $200 \mathrm{mg}$ aceclofenac sustained release formulation in relation to a commercial brand of $100 \mathrm{mg}$ aceclofenac in male volunteers.

\section{EXPERIMENTAL}

\section{Materials}

The reference aceclofenac product used was an immediate release Zerodolß $100 \mathrm{mg}$ filmcoated tablets, supplied (Ipca Laboratories, Mumbai, India). Aceclofenac was a gift from Mepro Pharmaceuticals Pvt. Ltd. Surendranagar, India. The excipients used in the production of the tablets were hydroxypropyl methylcellulose (HPMC) viscosity grade 4000 cps, (Methocel K4M, Colorcon Asia Pvt Ltd, Singapore) and lactose (DMV International, USA). Others were polyvinyl pyrollidone (PVP) K-30, (International Fine Chemicals Inc,, Canada), sodium propyl paraben (Salicylates and Chem Pvt Ltd, India), fumaric acid, magnesium stearate (Nitika Chemicals, India), talc (Udaipur Mineral Development Syndicate Pvt Ltd, India), colloidal silicon dioxide (Aerosil), isopropyl alcohol (Ranbaxy Fine Chemicals, India), methylene chloride (Chemplast Sanmar Ltd, India) titanium dioxide (Dupont Company Pvt Ltd, Singapore), PEG-6000 (Manali Petro Chemicals, India), castor oil (Sundarballi Oil Mill, India) and Ponceau $4 \mathrm{R}$ supra (Roha Dye Chem, India). All other chemicals used were of analytical grade.

\section{Preparation of aceclofenac sustained release tablets}

The tablets were prepared by a wet granulation technique. The composition of the tablet formulations are given in Table 1. Aceclofenac, Methocel K4M, lactose/maize starch, sodium propyl para benzoate and fumaric acid were screened through a 425 $\mu \mathrm{m}$ sieve and mixed manually in a bowl for 5 min. The blend was granulated with the aid of PVP K-30 and water. The mass was sieved through a $500 \mu \mathrm{m}$ sieve and then dried in a hot air oven at $50{ }^{\circ} \mathrm{C}$. Magnesium stearate, talc and colloidal silicon dioxide were then added to the dried granules, mixed for about 5 min in a polythene bag and compressed into tablets using a 12- station tablet compression machine (CIP Machineries, Ahmadabad, India) equipped with a $11 \mathrm{~mm}$ biconcave-faced punches. To mask the bitter taste of the aceclofenac, the tablets were coated in a laboratory coater (Model GAC250, Gansons Ltd, Mumbai, India) with HPMC 5cps dissolved in a mixture of isopropyl alcohol and methylene chloride; titanium dioxide and Ponceau $4 \mathrm{R}$ supra (colouring agents) as well as polyethylene glycol (PEG) 6000 and castor oil (plasticizers) were also incorporated in the coating mixture prior to coating. 
Table 1: Composition of sustained release tablet formulations

\begin{tabular}{lc}
\hline Ingredient & Weight $\mathbf{( m g )}$ \\
\hline Aceclofenac & 200 \\
Methocel K4M & 37.5 \\
Colloidal silicon dioxide & 4 \\
Maize starch & 33 \\
Lactose & 30 \\
Purified water & q.S. \\
Povidone ( PVPK-30) & 7.5 \\
Sodium propyl paraben & 2 \\
Fumaric Acid & 10 \\
Magnesium stearate & 4 \\
Talc & 5 \\
\hline
\end{tabular}

Compressing weight: $325 \mathrm{mg}$

\section{Physiochemical characterization of the tablets}

Tablet weight variation was evaluated on ten randomly selected tablets with an electronic balance (Mettler Toledo, Mettler, Griefensee, Switzerland) while tablet hardness and friability were also determined for ten randomly selected tablets using a Monsanto tablet hardness tester (standard type) and a Campbell electronic friabilator for $4 \mathrm{~min}$ at 25 rpm, respectively. Tablet diameter was evaluated with a digital vernier caliper.

\section{Subjects and ethical issues}

This study was performed in accordance with United States Food and Drugs Administration (FDA) Good Clinical Practice guidelines. Volunteers enrolled for this study were appraised in detail about all aspects of the study in easy to understand language and terminologies. Before admission to the study each subject was informed of the nature and the risks of the study and a written informed consent was obtained from the volunteers. The study involved twenty four healthy, adult, non-smoking male volunteers (mean age: $32.25 \pm 5.53$ years; mean height: $165.25 \pm$ $3.96 \mathrm{~cm}$; and mean weight: $62.25 \pm 3.96 \mathrm{~kg}$ ) with no revealed medical abnormality. The experimental protocol was approved by the instituional Central Ethics Committee (ref no. CEC/05/018) and the study was conducted at the Drug Monitoring Research Institute (DMRI), Sion, Mumbai, India.

\section{Study design}

All the volunteers were housed at the study centre. They were randomly divided into 2 groups of 12 subjects each. After an overnight fast $(10 \mathrm{~h})$, each group received orally, with $250 \mathrm{ml}$ of water, either a single dose of the test sustained-release formulation or the reference product in a randomized fashion, using a two-treatment, two-way crossover study design. A sevenday washout period was allowed between dosing schedules.

\section{Sample collection and handling}

Blood samples $(2 \mathrm{ml})$ were collected by the intravenous route using heparinized disposable syringes at the following times: 0 , $0.5,1.0,1.5,2,3,4,5,6,8,10,12,16,18$, 20 and 24 hours after drug administration. The blood samples were collected in vacutainers containing EDTA as anticoagulant and immediately centrifuged at $3000 \mathrm{rpm}$ for $15 \mathrm{~min}$. The separated plasma samples were stored at $-20^{\circ} \mathrm{C}$ until analysed.

\section{Preparation of standard solutions}

A stock solutions $(1 \mathrm{mg} / \mathrm{mL})$ of aceclofenac was prepared with methanol as the solvent. From the stock solution, standard solutions were prepared to contain 1, 2, 5, 10, 20, 30, 50 and $70 \mu \mathrm{g} / \mathrm{mL}$ of aceclofenac. A solution of ibuprofen $(500 \mu \mathrm{g} / \mathrm{mL})$ was prepared in a methanol/water mixture (80:20) and used as internal standard in the assay of aceclofenac.

\section{Analysis of drug in plasma}

To $100 \mu \mathrm{L}$ of plasma, $25 \mu \mathrm{L}$ of the internal standard and $200 \mu \mathrm{L}$ of acetonitrile were added and mixed for a minute, and then made up to $1 \mathrm{ml}$ with acetonitrile. The resulting solution was vortexed for $60 \mathrm{~s}$ and centrifuged at $10,000 \mathrm{rpm}$ for $10 \mathrm{~min}$. The supernatant layer was separated and 
analyzed for aceclofenac content using a sensitive high performance liquid chromatographic (HPLC) method with a Shimadzu Class VP series incorprating Class VP 6.12 version software, two pumps (LC10AT VP), a variable wavelength programmable UV detector (SPD-10A VP), a system controller (SCL-10A VP) and an RP C-18 column (Hypersil BDS C18). The operating conditions and parameters include: mobile phase: methanol $+0.3 \%$ tri ethyl acetic acid (60:40 v/v, pH 7.0); flow rate: 1.0 $\mathrm{mL} / \mathrm{min}$; injection volume: $20 \mathrm{~mL}$; temperature: $25{ }^{\circ} \mathrm{C}$; run time: $25 \mathrm{~min}$; detection wavelength: $275 \mathrm{~nm}$; and internal standard - ibuprofen. The response factor was measured by the ratio of the peak area of drug to that of the internal standard for both standard and test samples. Blank plasma samples were analyzed prior to the analysis of the standard and test preparations. Preliminary studies had shown that the presence of plasma did not interfere with the analysis of the drugs. The peaks were well resolved and the retention times were $5 \mathrm{~min}$ (aceclofenac) and $10.5 \mathrm{~min}$ (ibuprofen).

\section{Data analysis}

Using the non-compartmental approach, plasma levels of aceclofenac were employed to compute their individual disposition kinetics, viz, $\mathrm{C}_{\max }$ (maximum plasma concentration), $T_{\max }$ (time to reach maximum plasma concentration), AUC 0 -t (area under plasma concentration-time curve), AUC ${ }_{0-\infty}$ (area under plasma concentration time curve, 0 to infinity), $\mathrm{K}_{\mathrm{el}}$ (elimination rate constant) and $t_{1 / 2}$ (elimination half-life). Pharmacokinetic parameters were calculated with PK Solutions 2.0 ${ }^{\mathrm{TM}}$ Noncompartmental pharmacokinetic data analysis software.

Student's t-test was employed to analyze the results using Graph Pad Instat Software, version 1.13. Differences below the probability level of 0.05 were considered statistically significant. The ratios of the mean bioavailability parameters (test : standard) were obtained and $90 \%$ confidence interval was used to determine bioequivalence. Log (natural) transformation of $\mathrm{C}_{\max }$ and $\mathrm{AUC} \mathrm{C}_{0-\infty}$ were performed prior to the statistical analysis. The equivalence criteria range was 80 to $125 \%$ based on FDA guidelines. Calculations also included area under curve (AUC) from time t to $\infty$ (infinity) calculated with poly-exponential and trapezoidal methods.

\section{RESULTS}

\section{Physicochemical properties of the formulated tablets}

Tablet thickness was in the range $3.6-3.9$ $\mathrm{mm}$; diameter, $11.0 \mathrm{~mm}$; and hardness, 5.0 $8.0 \mathrm{~g} / \mathrm{cm}^{2}$. Tablet friability and coefficient of weight variation (for individual tablets) were 0.5 and 1.4 to $3.5 \%$, respectively. Drug content $(99-100 \%)$ was uniform.

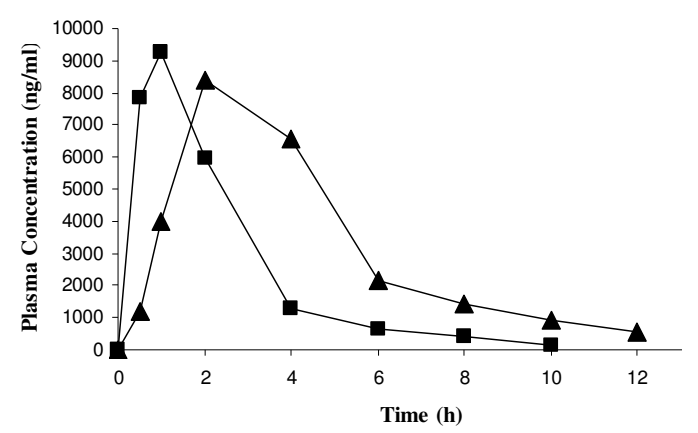

Figure 1: Mean plasma concentration versus time profile of test aceclofenac SR tablets 200 $\mathrm{mg}(\mathbf{\Lambda})$ and reference standard tablets ( $\mathbf{a})$

\section{Pharmacokinetic profiles of aceclofenac tablets}

Administration of the reference product as a single dose produced $C_{\max }$ of $12301 \pm 3000$ $\mathrm{ng} / \mathrm{ml}$ at a $t_{\max }$ of $1.29 \pm 0.75 \mathrm{~h}$ while $C_{\max }$ for the test preparation was $11043 \pm 3073$ $\mathrm{ng} / \mathrm{ml}$ at a $t_{\max }$ of $2.58 \pm 1.22 \mathrm{~h}$ (Table 2). The bioavailability of the test preparation relative to that of the standard was $91.1 \%$. $\mathrm{C}_{\max }$, $A \cup C_{0-t}$ and $A \cup C_{0-\infty}$ values of the test 
preparation were 96.4 - $101.3 \%, 100.2$ $101.9 \%$ and $98.5-99.8 \%$ of that of the reference, as shown in Table 3.

Table 2: Pharmacokinetic parameters for the test (A) and reference standard formulations (B)

\begin{tabular}{lll}
\hline Parameter & B (mean \pm SD) & A (mean \pm SD) \\
\hline $\mathrm{C}_{\max }(\mu \mathrm{g} / \mathrm{ml})$ & $12301 \pm 3000$ & $11043 \pm 3073$ \\
$\mathrm{t}_{\max }(\mathrm{h})$ & $1.29 \pm 0.75$ & $2.58 \pm 1.22$ \\
$\mathrm{AUC}_{0-\mathrm{t}}$ & $47766 \pm 7891$ & $43526 \pm 10561$ \\
$(\mathrm{ng} \cdot \mathrm{h} / \mathrm{ml})$ & & \\
$\begin{array}{l}\mathrm{AUC} \mathrm{C}_{0-\infty} \\
(\mathrm{ng} \cdot \mathrm{h} / \mathrm{ml})\end{array}$ & $50253 \pm 8283$ & $45997 \pm 10427$ \\
$\mathrm{kel}_{\mathrm{el}}\left(\mathrm{h}^{-1}\right)$ & $0.427 \pm 0.245$ & $0.238 \pm 0.183$ \\
$\mathrm{t}_{1 / 2}(\mathrm{~h})$ & $2.20 \pm 1.25$ & $4.50 \pm 2.59$ \\
\hline
\end{tabular}

Table 3: Bioavailability data for test aceclofenac formulation $(200 \mathrm{mg})$ relative to the reference at $90 \%$ confidence interval

\begin{tabular}{ll}
\hline Parameter & Log transformed data \\
\hline $\mathrm{C}_{\max }$ & $96.4-101.4 \%$ \\
$\mathrm{AUC} \mathrm{C}_{0-\mathrm{t}}$ & $100.2-101.9 \%$ \\
$\mathrm{AUC} \mathrm{C}_{0-\infty}$ & $98.5-99.8 \%$ \\
\hline
\end{tabular}

\section{DISCUSSION}

Aceclofenac was available in plasma within half an hour after its oral administration. The $t_{\max }$ of the test aceclofenac was significantly different $(p<0.05)$ from that of the standard. Low $t_{\max }$ value for the reference drug $(1.29 \mathrm{~h})$ indicates rapid absorption while the higher $t_{\max }$ of the test drug $(2.59 \mathrm{~h})$ suggests slower absorption. This delayed absorption of test preparation is most likely due to the sustained release of the drug. On the other hand, the $\mathrm{C}_{\max }$ of reference formulation was not significantly different from the test preparation. The half-life of the reference preparation was low which indicates rapid removal of the drug from plasma. This was also supported by the high elimination rate constant value. On the other hand, the test formulation exhibited higher half-life and low elimination rate constant values indicating slower drug disposition and prolonged effect. However, the $\mathrm{AUC}_{0-\infty}$ values for the two formulations were not significantly different. There was also no difference in the extent of absorption for both the test and reference products as indicated by the less than $10 \%$ difference in relative bioavailability $(91.1$ versus $100 \%$ ) of the drug. This suggests that the aceclofenac contained in the test product was completely absorbed.

\section{CONCLUSION}

The test product showed sustained release characteristics unlike the reference. Overall, the pharmacokinetic profile of the former was either equivalent or superior to that of the reference. Thus, the test aceclofenac preparation can be further developed to achieve a suitable sustained release product.

\section{ACKNOWLEDGMENT}

The authors wish to acknowledge M/s Mepro Pharmaceuticals Pvt Ltd, Surendranagar Gujarat, India, for providing the reference standard and pure aceclofenac used in the study.

\section{REFERENCES}

1. Brogden RN, Wiseman LR. Aceclofenac: A review of its pharmacodynamic properties and therapeutic potential in the treatment of rheumatic disorders and in pain management. Drugs 1996; 52(7): 113-124.

2. Mutalik S, Naha A, Usha A N,. Ranjith A K, Musmade $P$, Manoj K, Preparation, In vitro, Preclinical and Clinical Evaluations of Once Daily Sustained Release Tablets of Aceclofenac, Arch Pharm Res. 2007; 30( 2): 222-234.

3. MHRA PAR- Aceclofenac100mg tablets, $P L$ 04416/0591, UKPAR, [Internet][ cited 2009 Nov 3] Available from: http://www.mhra.gov.uk/ home/groups/l-unit1/documents/websiteresource s /con2023359.pdf.

4. British National Formulary (BNF 41) British Medical Association: London, 2001; p 464.

5. European Pharmacopoeia, 4th ed., Council of Europe, Strasbourg Cedex: France. 2002; $p 1281$.

6. British Pharmacopoeia, Vol I, Her Majesty's Stationary Office: London. 2002; p 35-37. 